\title{
Combined Use of Western Blot/ELISA to Improve the Serological Diagnosis of Human Tuberculosis
}

S. T. Beck' ${ }^{1}$ O. M. Leite ${ }^{2}$, R. S. Arruda ${ }^{3}$, and A. W. Ferreira ${ }^{4}$

\author{
${ }^{1}$ Federal University of Santa Maria, Santa Maria, RS; ${ }^{2}$ Clinical \\ Hospital - Faculty of Medicine of São Paulo University, São \\ Paulo; ${ }^{3}$ Clinical Hospital, São Paulo; ${ }^{4}$ Biolab-Merieux S/A and \\ Tropical Medicine Institute, São Paulo, SP, Brazil
}

\begin{abstract}
Two recombinant antigens and a crude bacterial antigen of a wild $M$. tuberculosis strain were used to detect specific IgG antibodies in sera from 52 patients with pulmonary tuberculosis, confirmed by an acid-fast smear and serum culture of these patients and that of 25 contacts. The patients were not infected with HIV. We evaluated the sensitivity and specificity of ELISA, based on the recombinant TbF6 $®$ and TbF6/DPEP antigen and a search for reactivity patterns in the Western blot technique, using whole mycobacterium antigen. Serum samples from 22 healthy individuals and from 30 patients with lung diseases other than tuberculosis were used as controls. The best ELISA results were obtained with the TbF6/DPEP antigen combination, which gave $85 \%$ sensitivity and $91 \%$ specificity. ELISA sensitivity improved from $85 \%$ to $92 \%$ when the Western blot results were used. Western blot specificity was $100 \%$ when antibody reactivity with different antigenic bands was analyzed and associated. The association of TbF6/DPEP antigens used in ELISA with specific patterns of reactivity determined by Western blot can help make an identification when classic methods for the diagnosis of pulmonary tuberculosis are not sufficient. Key Words: M. tuberculosis; recombinant antigens; diagnosis.
\end{abstract}

Mycobacterium tuberculosis causes pulmonary tuberculosis ( $\mathrm{Tb}$ ), and the clinical manifestations of infection can be either acute, or latent and asymptomatic, depending on the intensity of the immune response mounted by the infected patient.

After being exposed to M. tuberculosis, $40 \%$ of the individuals that become infected will develop primary active tuberculosis, and $60 \%$ remain with the latent form of the bacilli and may present extrapulmonary sites of infection, resulting from inefficient macrophage action at the beginning of exposure [1].

Received on 18 August 2004; revised 19 November 2004. Address for correspondence: Dr. Sandra Trevisan Beck. Universidade Federal de Santa Maria . Centro de Ciências da Saúde, Departamento de Análises Clínicas e Toxicológicas, Campus Universitário - Camobi, Santa Maria - RS, Zip code: 97105-900. Phone: (55) 220 8464 E-mail: sbeck@ig.com.br

The Brazilian Journal of Infectious Diseases 2005;9(1):35-43 (C) 2005 by The Brazilian Journal of Infectious Diseases and Contexto Publishing. All rights reserved.
Considering that one-third of the world population carries M. tuberculosis in its latent form, and that $5 \%$ develop active disease during the first years of infection, it is estimated that 8 million new cases of tuberculosis and 3 million deaths occur each year. Furthermore, the risk of reactivation increases as a consequence of associated conditions and pathologies [2], such as diabetes, cancer, chronic renal insufficiency, immunesuppressive therapy, malnutrition and, mainly, coinfection with human immunodeficiency virus (HIV) [3].

The standard diagnosis is still made by clinical examination, direct sputum microscopy, and bacterial culture. However, tuberculosis does not always present the classic radiological signs that allow an easy diagnosis, especially in extrapulmonary cases. The traditional laboratory methods used for complementation of diagnosis have their limits, such as low sensitivity of acidfast smears in paucibacillary patients, the time needed for cultivation, with undetectable growth in only 10 to $20 \%$ of the cases, and the high costs involved in molecular detection methods, such as PCR. 
The purified protein derivative (PPD) skin test is of limited value, since it can turn positive in people who have been vaccinated with bacillus Calmette-Guerin (BCG) and in individuals who have had contact with other mycobacteria [4].

Many studies have focused on the detection of antibodies specific for different $M$. tuberculosis antigens that indicate active disease. Such a rapid serologic test should be economic and successful in cases where the classical methods are not sufficient. According to the recommendations of the World Health Organization, to replace the "gold standard", bacterial culture, a serological test must possess a sensitivity of over $80 \%$ and specificity of over $95 \%$ [5].

In attempts to develop a serological test, mycobacterial antigens, such as $38 \mathrm{kDa}$ Phos[6], 30 $\mathrm{kDa}$ antigen 6, 85B [7], $16 \mathrm{kDa}$ [8], LAM [9], A60 [10], and Mtb81 [11], have been characterized, purified and independently tested with sera obtained from tuberculosis patients. Not long ago, research focused on low-molecular weight antigens that are specific and potentially useful for the diagnosis of tuberculosis, such as the antigens, $23 / 24 \mathrm{kDa}, 19 \mathrm{kDa}, 14 \mathrm{kDa}(16 \mathrm{kDa})$; Mtb 8 and ESAT-6 (a 6 kDa MW secreted antigen) $[12,13]$. The observed heterogeneous immune response, together with the absence of reactivity to a single antigen, or with a specific group of antigens, suggests the existence of variations among individuals as well as variability according to the stage of the disease [14].

Many researchers have suggested that one possibility to compensate for the variation of the immune response and the influence of the stage of the disease would be to combine the antigens with the highest individual sensitivities into one single test. This antigen mixture would improve the test performance by allowing simultaneous recognition of the different epitopes of each of the proteins [15]. The profile of antibody reactivity has been exhaustively studied using different antigen preparations in Western blotting $[16,17]$.

All of these publications have shown that at least $90 \%$ of patients produce specific IgG during the pathological process. Thus, the low sensitivity reported for the currently-used serological tests does not reflect a failure of the humoral immune response of the tuberculosis patient, but highlights the difficulties in elaborating a suitable test format.

We developed an ELISA based on the recombinant antigen TbF6 and on the TbF6/DPEP combination (Corixa ${ }^{\circledR}$ Co.), evaluated its performance in detecting IgG antibodies specific for M. tuberculosis and investigated by Western blot the IgG profiles of pulmonary tuberculosis patients and their contacts, using low molecular weight proteins extracted from a wild strain of $M$. tuberculosis as antigens.

We calculated the sensitivity, specificity, and positive and negative predictive values of this test for the diagnosis of $\mathrm{Tb}$ patients.

\section{Material and Methods}

\section{$\underline{\text { Mycobacteria }}$}

The M. tuberculosis strain employed in this study was isolated from a sputum sample obtained from a patient with tuberculosis in 2000 . The bacteria were cultivated on Löwenstein-Jensen medium at $37^{\circ} \mathrm{C}$ for 30 days. Species confirmation was performed using microbiological assays and a DNA hybridization test using a DNA probe specific for the $M$. tuberculosis complex (Accuprobe M. tuberculosis complex - GenProbe ${ }^{\circledR}$, cat. no. 2860).

Bacteria grown on Löwenstein-Jensen medium were inoculated in Sauton liquid medium. After incubation at $37^{\circ} \mathrm{C}$ for five weeks, the bacterial suspension was transferred to a 1-liter flask containing $250 \mathrm{~mL}$ of Sauton liquid medium and incubated at $37^{\circ} \mathrm{C}$ for another 10 weeks, without shaking.

\section{$\underline{\text { Crude bacterial antigen }}$}

Approximately $2 \mathrm{~g}$ of wet bacteria were harvested by centrifugation from the surface of the liquid culture, washed and resuspended in PBS containing PMSF, EDTA and DTT at final concentrations of $1 \mathrm{mM}$ each. The bacilli were subjected to sonication for $1 \mathrm{~h}$ at 80 
Hertz, using a Vibra Cell ${ }^{\mathrm{TM}} 72405$ sonicator (BioBlock Scientific) in ice, and subsequently centrifuged at 10,000 $\mathrm{x} g$ for $30 \mathrm{~min}$ at $4^{\circ} \mathrm{C}$. Proteins were precipitated by adding ammonium sulfate ( $80 \%$ final concentration) to the supernatant and resuspended in saline after centrifugation at $10,000 \times \mathrm{g}$ for $30 \mathrm{~min}$ at $4^{\circ} \mathrm{C}$. After dialysis for 24 hours against saline, using a D-7884 membrane (Sigma), the protein content was determined by the method of Lowry et al. [18].

\section{$\underline{\text { SDS-PAGE }}$}

Protein electrophoresis was carried out as described by Laemmli [19], using 18\% acrylamide/ bisacrylamide gels. The antigens were diluted in sample loading buffer without $\beta$-mercaptoethanol, heated to $95^{\circ} \mathrm{C}$ for two min. in loading buffer and loaded on the gel $(10 \mu \mathrm{L} / \mathrm{slot})$. Prestained Rainbow ${ }^{\mathrm{TM}}$ was used as a molecular weight marker in the range of 2,500 to 45,000 Da (Amersham Pharmacia Biotech, RPN 755).

\section{Western blot}

The SDS-PAGE-fractionated antigen mixture was transferred to a nitrocellulose membrane $(0.45 \mu \mathrm{m}$, BioAgency, \#162-0115n), as described by Towbin et al. [20]. Transfer efficiency was monitored by checking for the presence of prestained marker bands on the membrane. After transfer, the membrane was blocked for $15 \mathrm{~min}$ in PBS/Tween $20(0.05 \%)$ [PBST] containing 5\% skim milk, washed in PBST and cut into $4 \mathrm{~mm}$ wide strips. The strips were incubated with patient serum samples diluted $1 / 50$ in PBST containing $0.5 \%$ skim milk for 18 hours at $4^{\circ} \mathrm{C}$. After additional washes, the blots were incubated for two hours at room temperature with anti-human IgG antibody conjugated to peroxidase (1/1,000 in PBST/0.5\% skim milk). After another wash cycle, the blots were developed by adding $2 \mathrm{~mL}$ 4-chloronaphtol ( $3 \mathrm{mg} / \mathrm{mL}$ in methanol) in $10 \mathrm{mLPBS}$ and $4 \mu \mathrm{L}$ of $\mathrm{H}_{2} \mathrm{O}_{2}(30 \%)$ and incubated for $10 \mathrm{~min}$. in the dark. Washing the blot in distilled water stopped the reaction. All incubations were carried out under constant shaking.

\section{$\underline{\text { Recombinant antigens }}$}

Therecombinant antigen TbF6 (Corixa ${ }^{\circledR}$ Co.) consists of the fusion of four recombinant M. tuberculosis antigens in the following order: Ra3 $₫$ - 38kD - 38-1® - FL TBH4®. It is a polyprotein designed to incorporate four genes of interest (Mtb8, 38 kDa, Mtb11 and Mtb 48) into a single expression vector [21]. The recombinant antigen DPEP (Corixa ${ }^{\circledR}$ Co. $)$ is a proline-rich protein that has been identified as the MPT 32 antigen. Corixa Co. kindly supplied the antigens.

\section{Microplate coating}

Flat-bottom polystyrene microplates (Nunc-Immuno Module MaxiSorb F16 - Denmark) were coated with TbF6 (200 ng/well) and TbF6/DPEP (200 ng/well) in carbonate/bicarbonate buffer (0.05 M, pH 9.6) solution. The plates were incubated in a humid chamber at room temperature for two hours, and subsequently for another 18 hours at $4^{\circ} \mathrm{C}$. Plates were then aspirated and blocked at $37^{\circ} \mathrm{C}$ for two hours in a humid chamber with $1 \%$ bovine serum albumin (BSA) in PBS, pH 7.2. After three washes with PBS containing $0.05 \%$ Tween 20 (PBS-T) and two washes with distilled water, the plates were either used immediately or wrapped and frozen at $-20^{\circ} \mathrm{C}$ until the time for use.

\section{$\underline{\text { ELISA }}$}

Serum was diluted 1/40 in PBS, pH 7.2, containing $0.1 \%$ BSA and $0.1 \%$ Tween-20, and $100 \mu \mathrm{L}$ was added to the wells and incubated for $30 \mathrm{~min}$. at room temperature. This was followed by washing five times with PBS-T and then incubating with $100 \mu \mathrm{L}$ of antihuman IgG-peroxidase conjugate (1/10,000 in sample dilution buffer) for a further $30 \mathrm{~min}$. at $37^{\circ} \mathrm{C}$. Plates were then washed five times in PBS-T and incubated in the dark with $100 \mu \mathrm{L}$ of tetra-methylbenzidine substrate for a further $30 \mathrm{~min}$. The reaction was stopped by the addition of $50 \mu \mathrm{L}$ of $2 \mathrm{~N} \mathrm{H}_{2} \mathrm{SO}_{4}$ to each well. The plates were read with a microplate reader (Titertek Multiscan® MCC/340) at $450 \mathrm{~nm}$. The cutoff and the adequate dilution were determined after analysis of the 
optical densities (OD) and corresponded to the average OD obtained for the control serum plus two standard deviations.

The cutoff was determined based on the analysis of ROC curves.

\section{Study population}

\section{Human sera}

All samples were collected after approval by the local Ethics Committee and after obtaining informed consent from the patients.

a) Patients. Fifty-two HIV-negative patients with a confirmed diagnosis of pulmonary tuberculosis at the University Hospital of Sao Paulo between 2000 and 2002 were selected for the study. Forty-one patients were smear and culture positive and 11 patients were smear negative and culture positive. The median age of the patients was 37 years (range, from 14 to 75 years), 41 patients $(80.5 \%)$ had radiological evidence and 22 patients $(43 \%)$ had cavity lesions. All samples were collected before treatment.

b) Contacts. Sixteen samples were obtained from household contacts of tuberculosis patients, and another nine samples were from individuals occupationally exposed to tuberculosis.

c) Control group. Serum samples were obtained from healthy individuals $(n=22)$ and from patients with other lung diseases $(n=30)$.

\section{$\underline{\text { Statistical methods }}$}

The results are expressed as percentages where appropriate. Means and standard deviations (SD) were also calculated.

\section{Results}

Serological profiles of IgG antibodies against low molecular weight antigenic fractions of M. tuberculosis were observed in different groups.
Among the sera from 52 patients with proven pulmonary tuberculosis, serum from one patient did not react with any protein fraction between 45 and 2.5 $\mathrm{kDa}$ and was ELISA and smear negative. The reagent serum predominantly recognized antigen fractions with a molecular weight between $38 \mathrm{kDa}$ and $6 \mathrm{kDa}$. Before treatment, Western blot analysis showed that $30(58 \%)$ of the patients produced specific IgG antibodies against antigens in the $6 \mathrm{kDa}$ range, $26(50 \%)$ against antigens in the $16 \mathrm{kDa}$ range, and $31(60 \%)$ against antigens in the $38 \mathrm{kDa}$ range.

The cut offs for TbF6 $®$ and TbF6/DPEP ELISA were calculated from the ROC curve (Figure 1).

When ELISA was performed using the TbF6 ${ }^{\circledR}$ antigen, 36 (69\%) of the patients' sera gave a positive result. This antigen detected five patients who were smear negative/culture positive. The positive predictive value for this antigen was $95 \%$ and the negative predictive value, $55 \%$.

With the TbF6/DPEP association, 44 (85\%) out of 52 patient sera gave positive results. Nine of them were smear negative/culture positive. The positive predictive value for this antigen association was $96 \%$ and the negative predictive value $71 \%$. Both antigens gave $91 \%$ specificity (Table 1).

Fourteen of 25 sera obtained from contacts reacted predominantly with antigens in the range between 38 $\mathrm{kDa}$ and $6 \mathrm{kDa}$

Among the 22 healthy individuals, $12(54.5 \%)$ had antibodies against the $26 \mathrm{kDa}, 38 \mathrm{kDa}, 16 \mathrm{kDa}$ or 6 $\mathrm{kDa}$ antigens at different frequencies. Skin test results (PPD) were not considered. Serum from 20 individuals did not react with any antigens in the molecular weight range under investigation.

Of the 30 patients with other lung diseases (lung carcinoma, silicosis, asthma or bronchitis), 11 (36\%) did not react with any antigen in the molecular weight range studied (Table 2).

Serum from $46(88 \%)$ of the 52 tuberculosis patients reacted simultaneously with at least two proteins. Three patterns of reactivity were only observed in this patient group: (38-16-6 kDa) (38-16 kDa) (38-6 kDa). Another pattern $(16-6 \mathrm{kDa})$ was observed in sera from patients and contacts. Four ELISA TbF6/DPEP- 
Figure 1. ROC curve of TbF6 ${ }^{\circledR}$ and TbF6/DPEP antigens.

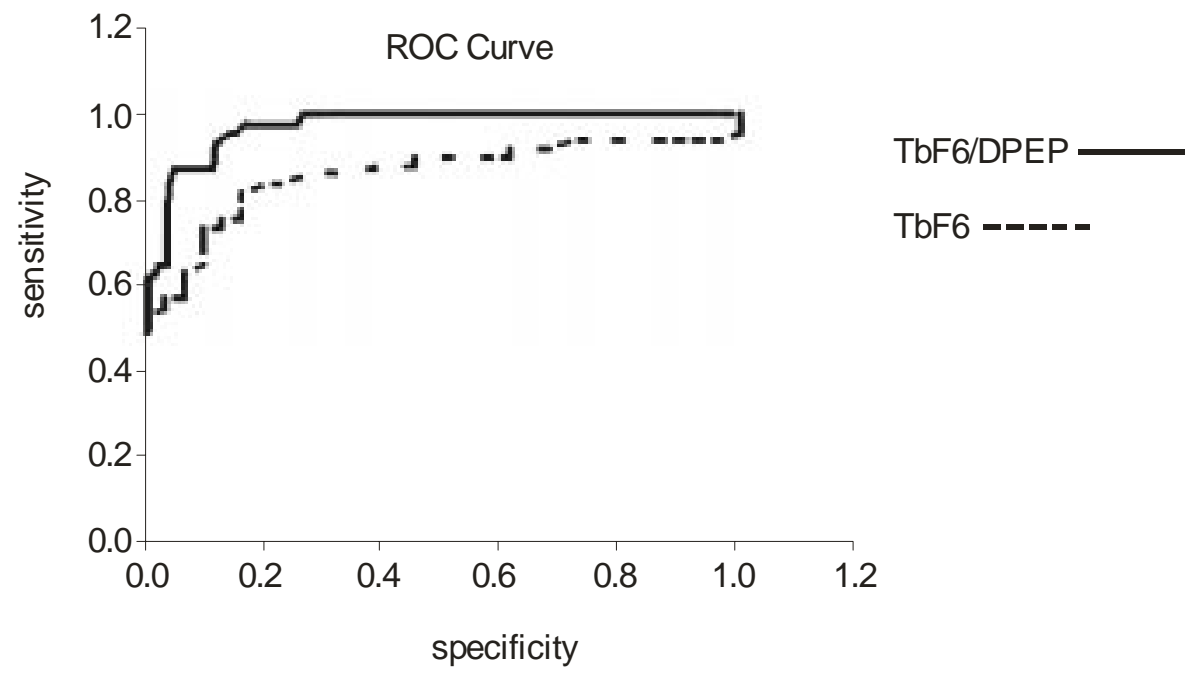

Table 1. Serological and bacteriological results in patients with confirmed pulmonary tuberculosis

\begin{tabular}{|c|c|c|c|c|c|c|c|c|c|c|}
\hline & \multicolumn{10}{|c|}{ Patients with positive bacteriology $(n=52)$} \\
\hline & \multicolumn{5}{|c|}{ TbF6 Ag (n) } & \multicolumn{5}{|c|}{ TbF6/DPEP Ag (n) } \\
\hline & $\begin{array}{c}\text { Smear } \\
+ \\
\text { Elisa } \\
+\end{array}$ & $\begin{array}{c}\text { Smear } \\
- \\
\text { Elisa } \\
+\end{array}$ & $\begin{array}{c}\text { Smear } \\
\text {-- } \\
\text { Elisa } \\
--\end{array}$ & $\begin{array}{c}\text { Smear } \\
+ \\
\text { Elisa } \\
-\end{array}$ & $\begin{array}{c}\text { Total } \\
\mathbf{N}\end{array}$ & $\begin{array}{c}\text { Smear } \\
+ \\
\text { Elisa } \\
+\end{array}$ & $\begin{array}{c}\text { Smear } \\
-- \\
\text { Elisa } \\
+\end{array}$ & $\begin{array}{c}\text { Smear } \\
-- \\
\text { Elisa } \\
--\end{array}$ & $\begin{array}{c}\text { Smear } \\
+ \\
\text { Elisa } \\
--\end{array}$ & $\begin{array}{c}\text { Total } \\
\mathbf{N}\end{array}$ \\
\hline \multicolumn{11}{|c|}{$\begin{array}{l}\text { WB Patterns } \\
(\mathrm{kDa})\end{array}$} \\
\hline $38-16-6$ & 5 & 1 & 0 & 1 & 7 & 6 & 1 & 0 & 0 & 7 \\
\hline $38-16$ & 7 & 0 & 0 & 1 & 8 & 7 & 0 & 0 & 1 & 8 \\
\hline $38-6$ & 6 & 1 & 1 & 3 & 11 & 7 & 2 & 0 & 2 & 11 \\
\hline $16-6$ & 7 & 0 & 0 & 1 & 8 & 7 & 0 & 0 & 1 & 8 \\
\hline $26-6$ & 2 & 0 & 1 & 1 & 4 & 3 & 1 & 0 & 0 & 4 \\
\hline $26-38$ & 2 & 0 & 1 & 2 & 5 & 3 & 0 & 1 & 1 & 5 \\
\hline $26-16$ & 1 & 1 & 0 & 1 & 3 & 2 & 0 & 1 & 0 & 3 \\
\hline 6 & 0 & 0 & 0 & 0 & 0 & 0 & 0 & 0 & 0 & 0 \\
\hline 16 & 0 & 0 & 0 & 0 & 0 & 0 & 0 & 0 & 0 & 0 \\
\hline 26 & 1 & 2 & 2 & 0 & 5 & 0 & 4 & 0 & 1 & 5 \\
\hline 38 & 0 & 0 & 0 & 0 & 0 & 0 & 0 & 0 & 0 & 0 \\
\hline None & 0 & 0 & 1 & 0 & 1 & 0 & 1 & 0 & 0 & 1 \\
\hline Total $(\mathrm{n}=)$ & 31 & 5 & 6 & 10 & 52 & 35 & 9 & 2 & 6 & 52 \\
\hline
\end{tabular}

$+=$ Positive result; . - = negative result; $n=$ number of patients present in the described profile. 
Table 2. Results of Western blot (WB) patterns and ELISA IgG anti TbF6® and TbF6/DPEP antigen for healthy individuals, contacts and patients with other lung diseases

\begin{tabular}{|c|c|c|c|c|c|c|c|c|c|c|c|c|}
\hline \multirow[b]{3}{*}{$\begin{array}{l}\text { WB Pattern } \\
(\text { kDa })\end{array}$} & \multicolumn{4}{|c|}{ Healthy $(n=22)$} & \multicolumn{4}{|c|}{ Contacts $(n=25)$} & \multicolumn{4}{|c|}{ Other lung disease $(n=30)$} \\
\hline & \multicolumn{2}{|c|}{ TbF6 } & \multicolumn{2}{|c|}{ TbF6/DPEP } & \multicolumn{2}{|c|}{ TbF6 } & \multicolumn{2}{|c|}{ TbF6/DPEP } & \multicolumn{2}{|c|}{ TbF6 } & \multicolumn{2}{|c|}{ TbF6/DPEP } \\
\hline & $\begin{array}{l}\text { Elisa } \\
+\end{array}$ & $\begin{array}{l}\text { Elisa } \\
--\end{array}$ & $\begin{array}{l}\text { Elisa } \\
+\end{array}$ & $\begin{array}{l}\text { Elisa } \\
--\end{array}$ & $\begin{array}{l}\text { Elisa } \\
+\end{array}$ & $\begin{array}{l}\text { Elisa } \\
--\end{array}$ & $\begin{array}{l}\text { Elisa } \\
+\end{array}$ & $\begin{array}{l}\text { Elisa } \\
--\end{array}$ & $\begin{array}{l}\text { Elisa } \\
+\end{array}$ & $\begin{array}{l}\text { Elisa } \\
--\end{array}$ & $\begin{array}{l}\text { Elisa } \\
+\end{array}$ & $\begin{array}{l}\text { Elisa } \\
--\end{array}$ \\
\hline $38-16-6$ & 0 & 0 & 0 & 0 & 0 & 0 & 0 & 0 & 0 & 0 & 0 & 0 \\
\hline $38-16$ & 0 & 0 & 0 & 0 & 0 & 0 & 0 & 0 & 0 & 0 & 0 & 0 \\
\hline $38-6$ & 0 & 0 & 0 & 0 & 0 & 0 & 0 & 0 & 0 & 0 & 0 & 0 \\
\hline $16-6$ & 0 & 0 & 0 & 0 & 1 & 1 & 0 & 2 & 0 & 0 & 0 & 0 \\
\hline $26-6$ & 0 & 1 & 0 & 1 & 0 & 0 & 0 & 0 & 0 & 0 & 0 & 0 \\
\hline $26-16$ & 0 & 2 & 0 & 2 & 2 & 0 & 1 & 1 & 0 & 1 & 0 & 1 \\
\hline $26-38$ & 0 & 2 & 0 & 2 & 1 & 2 & 0 & 3 & 0 & 1 & 0 & 1 \\
\hline 6 & 0 & 0 & 0 & 0 & 0 & 2 & 0 & 2 & 0 & 1 & 0 & 1 \\
\hline 16 & 0 & 0 & 0 & 0 & 0 & 0 & 0 & 0 & 0 & 0 & 0 & 0 \\
\hline 26 & 1 & 4 & 1 & 4 & 1 & 3 & 1 & 3 & 2 & 10 & 1 & 11 \\
\hline 38 & 0 & 2 & 0 & 2 & 0 & 1 & 0 & 1 & 1 & 3 & 1 & 3 \\
\hline None & 1 & 9 & 1 & 9 & 1 & 10 & 1 & 10 & 3 & 8 & 2 & 9 \\
\hline Total $(n=)$ & 2 & 20 & 2 & 20 & 6 & 19 & 3 & 22 & 6 & 24 & 4 & 26 \\
\hline
\end{tabular}

$+=$ Positive result $-=$ negative result $n=$ number of patients present in the described profile.

negative patients were positive by Western blot based on these patterns (Table 1).

Only seven out of 25 contacts reacted simultaneously with two fractions. Two individuals $(8 \%)$ reacted with antigens in the $6 \mathrm{kDa}$ and $16 \mathrm{kDa}$ regions, and another five with antigens in $26 \mathrm{kDa}$ and $16 \mathrm{kDa}$ or 26 and $38 \mathrm{kDa}$ range (Table 2 ).

In the group of healthy individuals, five $(23 \%)$ reacted simultaneously with antigens in the $26 \mathrm{kDa}$ region, associated with the $6 \mathrm{kDa}, 16 \mathrm{kDa}$ or $38 \mathrm{kDa}$ range. Two $(6 \%)$ out of 30 patients with other lung diseases reacted simultaneously with the bands mentioned above (Table 2).

Therefore, the positive predictive values for the combined analyses of the reactivity patterns were $100 \%$ for the $6+16 \mathrm{kDa}$ ranges, $100 \%$ for the $6+38 \mathrm{kDa}$ ranges and $100 \%$ for the $16+38 \mathrm{kDa}$ and the $38+16+6$ $\mathrm{kDa}$ ranges. The negative predictive values for these combinations were $46 \%(6+16 \mathrm{kDa})$ and $(38-16 \mathrm{kDa})$, $45 \%(38-16-6 \mathrm{kDa})$ and $49 \%(6+38 \mathrm{kDa})$.
Considering the presence of one of these patterns, the negative predictive value was $55 \%$.

\section{Discussion}

Many investigators have described the difficulties encountered with correctly diagnosing active $M$. tuberculosis infection [22]. For this reason, structural proteins and proteins that are excreted or secreted in vitro by $M$. tuberculosis, as well as recombinant or synthetic antigens, have been extensively investigated [23,24].

In our study, the ELISA based on the recombinant antigen $\mathrm{TbF} 6{ }^{\circledR}$ and the TbF6/DPEP association gave satisfactory specificity (91\%), when compared to the specificity values obtained in other studies with other antigens, such as A60 (88.4\%), $12 \mathrm{kDa}(97 \%), 38$ $\mathrm{kDa}(95 \%)$, and $16 \mathrm{kDa}(100 \%)$ [25-27]. Of 52 patients with confirmed active tuberculosis, 36(69\%) 
had antibodies against TbF6 $®$ antigen in serum samples collected before treatment. The TbF6/DPEP antigen association showed better results, with reagent serum samples in $44(85 \%)$ of the patients. This sensitivity is in agreement with that of other studies for the same association using serum from Brazilian patients [21] and is similar to the sensitivity described by Cole et al. [28] in a study carried out on patients with pulmonary tuberculosis in China. These authors found a sensitivity of $89 \%$ for smear-positive patients, and of $74 \%$ for smear-negative patients for the $38 \mathrm{kDa}$ antigen.

Various factors affect the capacity of a patient to mount a specific humoral immune response against $M$. tuberculosis. One of these factors is the stage of the disease. When cavity lesions appear, M. tuberculosis expresses certain antigens that are not expressed in earlier stages of the infection. Depending on the time of diagnosis, assays based on these antigens present different sensitivities, as has been mainly reported for HIV-positive patients who normally do not show cavity lesions [29].

Since many of these M. tuberculosis antigens show homology to proteins of other prokaryotes [30], one of the main problems for the detection of the humoral response to tuberculosis is the cross-reactivity observed for sera from healthy individuals. Studies using Western blotting analysis showed that sera from tuberculosis patients and healthy controls differed in their reactivities with $M$. tuberculosis antigens in the 43 and $12 \mathrm{kDa}$ range [31].

In view of these observations, we decided to investigate the humoral response of tuberculosis patients, and their contacts, to proteins with a molecular weight between 45 and $2.5 \mathrm{kDa}$ that are present in the soluble fraction of sonicated $M$. tuberculosis, including membrane and cytoplasm proteins.

In Western blot analysis, sera from 46 (88\%) patients reacted simultaneously with at least two proteins. Five of six patients who did not show associated reactivity were smear negative and four did not present cavity lesions. The only one who had a positive smear and reactive serum for TbF6® ELISA had autoimmune disease and was taking immunosuppressive medication (Table 1).
Antibodies against antigens in the $38 \mathrm{kDa}$ range were found in serum from $16 \%$ of the contacts and patients with other lung diseases. In the Tb patients, the reactivity frequency $(60 \%)$ observed for this protein was similar to that observed by others [32]. Its strong association with HLA antigens [33], and its relation with the presence of cavitary [34] processes, explains the variation in sensitivity values reported by different investigators, which depends on the population under investigation. For the antigens in the $16 \mathrm{kDa}$ range, we found 50\% reactivity. Verbon et al. [35] described a sensitivity of $73 \%$ for a purified $16 \mathrm{kDa}$ protein from M. tuberculosis, but not with synthetic peptides, suggesting reaction with conformational epitopes, a fact that can change the degree of reactivity.

In our study, we found that before treatment $58 \%$ of the patients produced antibodies against the $6-\mathrm{kDa}-$ range protein. Although the sensitivity observed for pretreatment samples was low, only patients with active pulmonary disease showed reactivity against the $6 \mathrm{kDa}$ region in association with the 38 and $16 \mathrm{kDa}$ regions. The association of these Western blot patterns with TbF6/DPEPELISA enhanced the sensitivity of the test to $92 \%$, detecting four cases that were not detected by ELISA but with a confirmed bacteriological diagnosis (Table 1). Antibodies that react exclusively with the $6 \mathrm{kDa}$ antigen were only sporadically detected in $9 \%$ of the healthy individuals and in $3 \%$ of patients with other lung diseases, all of them with negative ELISA results for both antigens.

Although $16 \%$ of the contacts presented antibodies specific for the $6 \mathrm{kDa}$ region, only two $(8 \%)$ of the 25 individuals presented an associated reactivity with the $16 \mathrm{kDa}$ region, one of them with a positive $\mathrm{TbF} 6 /$ ELISA (Table 2). These individuals suffered occupational exposure, and subclinical disease cannot be excluded. Lopez-Vidal et al. [36], studying the response to ESAT-6 and 38kDa recombinant proteins in tuberculosis patients and in asymptomatic household contacts, concluded that ESAT-6 recognition by HHC could indicate early-stage infections.

Concerning the $16 \mathrm{kDa}$ antigen, only $16 \%$ of the contacts and $4.5 \%$ of the healthy controls had reactive antibodies. An increase in $16 \mathrm{kDa}$ antibodies or 
antibodies specific for the TB68 epitope has been reported for healthy individuals after occupational exposure, and for household contacts of tuberculosis patients [12,35]. The presence of these antibodies in tuberculosis patients has been associated either with a more favorable prognosis or with spontaneous cure, since these antibodies disappeared after two years of treatment [37]. Further studies are necessary to determine how long this serological response remains in post-treatment patients.

To reduce the incidence of tuberculosis, the ability of an antigen to distinguish between sub clinical and active disease is as important as the sensitivity of the antigen in detecting antibodies formed during tuberculosis infection. Association of the ELISA TbF6/ DPEP test with the specific patterns of Western blot results in high sensitivity (92\%) for serodiagnosis purposes. The use of a highly specific test in a hospitalized patient population with suspected tuberculosis has the advantage that specific therapy can be initiated before culture or smear results become available. Furthermore, this test will be extremely important to make a decision regarding preventive therapy in contacts that do not present with clinical disease.

\section{References}

1. Orme I.M. The latent tuberculosis bacillus (I'll let you know if I ever meet one). Int $\mathrm{J}$ Tuberc Lung Dis 2001;5(7):589-93.

2. Rook G.A.W., Pando R.H. The Pathogenesis of tuberculosis. Annu Rev Microbiol 1996;50:259-84.

3. Badri M., Ehrlich R., Wood R., et al. Association between tuberculosis and HIV disease progression in a high tuberculosis prevalence area. Int J Lung Dis 2001;5(3):225-32.

4. Pottumarthy S., Morris A.J., Harrison A.C., Wells V.C. Evaluation of the tuberculin gamma interferon assay: potential to replace the Mantoux skin test. J Clin Microbiol 1999;37:3229-32.

5. World Health Organization. WHO Tuberculosis Diagnostics Work-shop: product development guidelines, 1997: 1-27. Workshop report (on line) www.who.int/tdr/publications. World Health Organization, Geneva, Switzerland.
6. Andersen A.B., Hansen E.B. Structure and mapping of antigenic domains of protein antigen b, a 38,000 molecular-weight protein of Mycobacterium tuberculosis. Infect Immun 1989;57:2481-8.

7. Salata R.A., Sanson A.J., Malhotra I.J., et al. Purification and characterization of the 30,000 kilodalton native antigen of $M$. tuberculosis and characterization of six monoclonal antibodies reactive with a major epitope of this antigen. J Lab Clin Med 1991;118:589-98.

8. Verbon A., Hartskeeri R.A., Moreno C., Kolk A.H. Characterization of $\mathrm{B}$ cell epitopes on the $16 \mathrm{~K}$ antigen of Mycobacterium tuberculosis. Clin Exp Immunol 1992;89:395-401.

9. Hunter S.W., Gaylord H., Brennan P.J. Structure and antigenicity of the phosphorylated lipopolysaccharide antigens from the leprosy and tubercle bacilli. J Clin Microbiol 1986;261:12345-51.

10. Cocito C., Vanlinden F. Preparation and properties of antigen 60 from Mycobacterium bovis BCG. Clin Exp Immunol 1986; 66:262-72.

11. Hendrickson R.C., Douglass J.F., Reynolds L.D., et al. Mass spectrometric identification of Mtb 81, a novel serological marker for tuberculosis. J Clin Microbiol 2000;38(6):2354-61.

12. Jackett P.S., Bothamley G.H., Batra H.V., et al. Specificity of antibodies to immunodominant mycobacterial antigens in pulmonary tuberculosis. J. Clin Microbiol 1988; $26: 2318-21$.

13. Arend S.M., Ottenhoff T.H.M., Andersen P., Dissel J.T.V. Uncommon presentation of tuberculosis: the potential value of a novel diagnostic assay based on the Mycobacterium tuberculosis-specific antigens ESAT6 and CPF-10. Int. J. Tuberc Lung Dis 2001;7:680-6.

14. Lyashchenko K., Colangeli R., Houde M., et al. Heterogeneous antibody responses in tuberculosis. Infect Immun 1998;66(8):3936-40.

15. Lyashchenko K.P., Singh M., Colangeli R., Gennaro M.L. A multi-antigen print immunoassay for the development of serological diagnosis of infection diseases. Journ Immun Methods 2000;242:91-100.

16. Rovatti E., Corradi M.P., Amicosante M., et al.. Evaluation of a western blot serum test for the diagnosis of Mycobacterium tuberculosis infection. Eur Respir J 1996;9(2):288-92.

17. Franco J., Camarena J.J., Nogueira J.M., et al. Serological response (Western blot) to fractions of Mycobacterium tuberculosis sonicate antigen in tuberculosis patients and contacts. Int J Tuberc Lung Dis 2001;5(10):958-62.

18. Lowry O.H., Rosebrough N.J., Farr A.L., Randall J. Protein measurement with the Folin phenol reagent .J Biol Chem 1951;193(1):265-75.

19. Laemmli U.K. Cleavage of structural proteins during the assembly of the head of bacteriophage T4. Nature 1970;226:680-5. 
20-. Towbin H., Staehelin T., Gordon J. Electrophoretic transfer of proteins from polyacrylamide gels to nitrocellulose sheets: procedure and some applications. Proc Natl Sci USA 1979;76: 4350-4.

21. Houghton R.L., Lodes M.J., Dillon D.C., et al Use of multiepitope polyproteins in serodiagnosis of active tuberculosis. Clin Diagn Lab Immunol 2002;9(4): 883-91.

22. Daniel M.T. Antibody and Antigen Detection for the Immunodiagnosis of Tuberculosis: Why Not? What More is Needed? Where Do we Stand Today? J Infect Dis 1988; $158(4)$ :678-80.

23. Andersen P., Askgaard D., Ljungqvist L., et al. Proteins Released from Mycobacterium tuberculosis during Growth. Infect Immun 1991;59(6):1905-10.

24. Singh K., Zhang X., Patibandla A.S., et al. Antigens of Mycobacterium tuberculosis expressed during preclinical tuberculosis: Serological immunodominance of proteins with repetitive amino acid sequences. Infect Immun 2001;69(6):4185-91.

25. Moran A.J., Treit J.D., Whitney J.L., et al. Assessment of the serodiagnostic potential of nine novel proteins from Mycobacterium tuberculosis. FEMS Microbiol Lett 2001;198:31-6.

26. Dillon D.C., Alderson M.R., Day C.H., et al. Molecular and immunological characterization of Mycobacterium tuberculosis CFP-10, and immunodiagnostic antigen missing in Mycobacterium bovis BCG. J Clin Microbiol 2000;38(9):3285-90.

27. Chian I.-H., Suo J., Bai K.-J., et al. Serodiagnosis of tuberculosis A study comparing three specific mycobacterial antigens. Am J Respir Crit Care Med 1997; 156:906-11.

28. Cole R.A., Lu H.M., Shi Y.Z., et al. Clinical evaluation of a rapid immunochromatographic assay based on the 38 $\mathrm{kDa}$ antigen of $M$. tuberculosis on patients with pulmonary tuberculosis in China. Tuberc Lung Dis 1996; 77:363-38.

29. Samanich K., Belisle J.T, Laal S. Homogeneity of antibody response in tuberculosis patients. Infect Immun 2001;69(7):4600-9.

30. Young D.B., Lathigra T., Garbe D., et al. Mycobacterial protein antigens: a compilation. Mol Microbiol 1992;6:133-45.

31. Bassey E.O.E, Catty D., Kumararatne D., Raykendalia C. Candidate antigens for improved serodiagnosis of tuberculosis. Tuber Lung Dis 1996;77:136-45.

32. Espitia C., Cervera I., Gonzales R., Mancilla R. A 38. kDa Mycobacterium tuberculosis antigen associated with infection. Its isolation and serological evaluation. Clin Exp Immunol 1989;77:373-7.

33. Bothamley G..H., Beck J.S, Schreuder G.M.T., et al. Association of Tuberculosis and M. tuberculosis specific antibody levels with HLA. J Infect Dis 1989;159(3):539-55.
34. Wilker H.G. Liberation of Soluble Protein from Live and Dead Mycobacterial Cell and the Implications for Pathogenicity of Tubercle Bacilli Scand J Immunol 2001;54:82-6.

35. Verbon A., Hartskeerl A.R., Moreno C., Kolk A.H.J. Characterization of $\mathrm{B}$ cell epitopes on the $16 \mathrm{~K}$ antigen of Mycobacterium tuberculosis. Clin Exp Immunol 1992;89:395-401.

36. Lopes-Vidal Y., Leon-Rosales S., Castañón-Arreola M., et al. Response of IFN $-\gamma$ and IgG to ESAT- 6 and $38 \mathrm{kDa}$ Recombinant Proteins and their Peptides from Mycobacterium tuberculosis in tuberculosis Patients and Asymptomatic Household contacts May Indicate Possible Early-Stage Infection in the Latter. Arch Med Res 2004;35:308-17.

37. Bothamley G..H., Rudd R., Festenstein F., Ivanyi J. Clinical value of the measurement of Mycobacterium tuberculosis specific antibody in pulmonary tuberculosis. Thorax 1992;47:270-5. 